\title{
SEMIOSFERA: PLIEGUE ENTRE MUNDO Y LENGUAJE
}

SEMIOSPHERE: CREASE BETWEEN WORLD AND LANGUAGE

\author{
Francisco López Cedeño ${ }^{1}$ \\ Universidad de Salamanca (España)
}

Recibido: 20-04-2013

Aceptado: 29-07-2013

Resumen: El hombre no puede estructurar la realidad haciendo abstracción de la lengua y de la cultura. Estas mantienen a la realidad en un movimiento continuo. La cultura es capaz de aislar este dinamismo y de ayudar al hombre a actuar porque refleja a la realidad en sí misma, la organiza ideológicamente, y hace mitos de la aventura humana. Si conociéramos los antagonismos que agitan la cultura, podríamos comprender mejor su naturaleza y su función.

Palabras-clave: Lotman, semiótica, semiosfera, códigos culturales de comunicación.

\begin{abstract}
Man can't structure reality by ignoring language and also culture. These keep reality in a perpetual motion. Culture is able to isolate such a dynamism helping man to take action because it is capable to reflect reality in itself to organize it in an ideologically way and to turn the human odyssey into a myth. If we'd achieve a suitable consciousness of the antagonisms that wave the culture, we also could reach a better knowledge of both, its nature and role.
\end{abstract}

Key-words: Lotman, semiotics, semiosphere, cultural codes of communication.

\section{Introducción}

En un primer momento mi interés estaba centrado en el libro de Benjamin Lee Whorf (Whorf 1971). Al estudiar comparativamente la lengua hopi y las lenguas europeas, este lingüista observó la relación entre la gramática hopi y la cultura de este pueblo amerindio, y entre las gramáticas de las lenguas europeas y la civilización occidental. Esto le llevó, tal como él resume, a plantearse dos cuestiones:

[1] (flcedenho@yahoo.es) Maestro por la Universidad de Granada, Licenciado en Filosofía por la UNED y Doctorando en la Facultad de Filología de la Universidad de Salamanca. Autor de artículos sobre Teoría de la Comunicación, Filosofía de la Educación, Filosofía de la Religión, Hermenéutica y Filosofías Orientales. 
"1) ¿Adquieren todos los hombres mediante la experiencia una idea sustancialmente similar a la de la civilización occidental sobre los conceptos de tiempo, espacio y materia? ¿O acaso estos conceptos están condicionados por la estructura de cada lengua en particular? 2) ¿Existen afinidades rastreables entre normas culturales y de comportamiento y modelos lingüísticos a gran escala?" (Whorf 1970: 160) ${ }^{2}$

Lotman presenta la relación entre la cultura y el lenguaje natural como uno de los problemas esenciales de su investigación y ha resaltado y analizado, basándose en la hipótesis Whorf-Sapir, la influencia del lenguaje sobre las diversas manifestaciones de la cultura humana. De hecho, considera que incluso la naturaleza del acto intelectual puede ser descrita como traducción de una lengua a otra (Lozano 2011: 176). Este primer enfoque de mis intereses varió por varios factores. No encontré suficiente material que profundizara en las hipótesis de Whorf. Éstas me atrajeron desde el primer momento en que supe de ellas a través de los textos de antropología cultural, sin embargo, el texto original no me pareció lo suficientemente sugerente; los conceptos principales (Lee 1996: 30-33) eran fascinantes, pero la obra no terminaba de convencerme. Me sorprendí, al comenzar a leer Dialogue at the margins (Schultz 1990: XI) de que las ideas que aparecen en las páginas preliminares expresen unas impresiones similares a las mías, que la escritora tuvo al leer los textos de Whorf, pero que ella resolvió enfrentándolas con las teorías de Bajtin y cuyo resultado es dicho ensayo.

Estas son las razones que me han llevado a interesarme más en el teórico de semiótica que hablaba de Whorf, Lotman, cuyo artículo "Sobre el mecanismo semiótico de la cultura" (Lotman 1979) es muy amplio en su visión, con referencias a las más diversas ciencias, y, aunque utiliza, por lo general, ejemplos de su propia tradición rusa, es aplicable a cualquier otra cultura. Por otra parte, sus textos no se acaban en sí mismos, sino que están llenos de ideas y de dudas que quedan sin resolver, de modo que se pueda continuar la investigación.

El semiólogo ruso y sus colaboradores proponen un proyecto semiótico diferente de los propuestos anteriormente a ellos, muy rico en perspectivas de desarrollo, impulsando posiciones hasta entonces minoritarias: el principio de la supremacía del texto, la constante referencia al contexto cultural, la atención prestada a la historia, y la conexión con la crítica filológica. Nuestra perspectiva general está centrada en las investigaciones de dichos teóricos.

[2] Ideas concomitantes llevan a Derrida a analizar la substantivación del verbo "ser", una situación lingüística de transcategorialidad que hace posible el nacimiento y despliegue de toda la metafísica griega del "ser". O a Benveniste a subrayar que no todas las lenguas disponen del verbo "ser". (Derrida 1989: 235-237). A propósito de este hecho relativo al verbo "ser" entre otros, y siguiendo el modelo de Whorf de comparación entre la lengua hopi y las lenguas que él denomina SAE -Standard Average European- analiza Moncef Chelli (Chelli 1980) las diferencias entre la civilización árabe y la occidental a través de un minucioso estudio de las respectivas gramáticas.

THÉMATA. Revista de Filosofía, Nº49 enero-junio (2014) pp.: 185-202 doi: 10.12795/themata.2014.i49.10 


\section{Cultura y texto}

La semiótica estudia todos los procesos culturales como procesos de comunicación (Eco 1975: 32). Y estamos excluyendo con esta definición dos formulaciones que pueden dar lugar a equívocos: "sistema de signos "y "sistema de comunicación".

Para demostrar que toda cultura es comunicación y que existe humanidad y sociabilidad solamente cuando hay relaciones comunicativas, Eco desarrolla dos ideas: a) toda cultura se ha de estudiar como un fenómeno de comunicación; b) todos los aspectos de una cultura pueden ser estudiados como contenidos de la comunicación.

En el momento en que se produce la comunicación entre dos hombres, es fácil imaginar que lo observable es el signo verbal o pictográfico, con el cual el emisor comunica al destinatario el objeto "piedra" y su posible función, por medio de un nombre. Con esto sólo llegamos a la segunda hipótesis: el objeto cultural se ha convertido en el contenido de una posible comunicación verbal. La primera hipótesis presupone, en cambio, que el emisor puede comunicar la función del objeto incluso sin denominarlo verbalmente, sino tan sólo mostrándolo. Esta primera hipótesis supone que desde el momento en que el posible uso de la piedra ha sido conceptualizado, la propia piedra se convierte en signo concreto de su uso virtual. Desde el momento en que existe la sociedad, cualquier función se convierte automáticamente en signo de tal función. Esto es posible porque hay cultura, pero existe la cultura porque esto es posible.

En cuanto al intercambio parental, por ejemplo, en el momento en que una mujer en algunas sociedades se convierte en esposa, ya no es solamente un cuerpo físico: es un signo que connota todo un sistema de obligaciones sociales.

Esta hipótesis convierte la semiótica en una teoría general de la cultura. No quiere decir que la cultura sea solamente comunicación, sino que ésta puede comprenderse mejor si se examina desde el punto de vista de la comunicación.

La segunda idea señala que todos los fenómenos de la cultura pueden convertirse en objetos de comunicación, es decir, cualquier aspecto de ella se convierte en una unidad semántica. Esta segunda idea remita a la primera. En la cultura cada entidad puede convertirse en un fenómeno semiótico. Las leyes de la comunicación son las leyes de la cultura. La semiótica es una disciplina que puede y debe ocuparse de la cultura, que, a su vez, puede ser considerada como una jerarquía de sistemas semióticos particulares, como una suma de textos a los cuales se une un conjunto de funciones, o, incluso, como un dispositivo que produce estos textos mismos. Si se considera una colectividad como un individuo construido de forma más compleja, la cultura puede ser interpretada, por analogía con el mecanismo individual de la memoria, como un dispositivo colectivo para conservar y elaborar la información (Morris 1984: 3). La

THÉMATA. Revista de Filosofía, Nº49 enero-junio (2014) pp.: 185-202 doi: 10.12795/themata.2014.i49.10 
estructura semiótica de la cultura y la estructura semiótica de la memoria son fenómenos, desde el punto de vista funcional, homogéneos, aunque situados en niveles diferentes. La mejor definición lotmaniana de cultura (Segre 1981: 17) es la del artículo "Sobre el mecanismo semiótico de la cultura":

\begin{abstract}
"El mecanismo semiótico de la cultura creado por la humanidad está organizado de formas substancialmente distintas (a los sistemas no-semióticos): se adoptan principios estructurales opuestos y alternativos. Sus relaciones, la disposición de estos o aquellos elementos en el campo estructural que se está formando crean la ordenación estructural que permite hacer del sistema el medio de conservación de la información. Y, sin embargo, es además esencial que sean realmente asignadas no estas o aquellas determinadas alternativas, cuyo número sería siempre finito y -para un sistema determinado- constante, sino el principio mismo de la alternancia, en base al cual todas las oposiciones concretas de una estructura dada representan sólo las interpretaciones en un determinado nivel. Por consiguiente, cualquier pareja de elementos, de ordenaciones locales, de estructuras particulares o generales, o bien de sistemas semióticos enteros, adquiere valor de alternativa y forma un campo estructural que puede ser llenado por la información." (Lotman 1979: 91)
\end{abstract}

Lotman ve la cultura como un texto único. ${ }^{3} \mathrm{Su}$ proyecto parece una consecuencia de la posición primaria, constitutiva incluso, que atribuye a los textos en cuanto cadena entre la semiótica literaria y la semiótica de la cultura. El texto, elemento primario y unidad de base de la cultura, ${ }^{4}$ debería ser considerado en relación a ella como un bloque inanalizable. Lejos de ser sucesión y combinación de signos (lingüísticos), el texto sería para la cultura un signo global, dotado de trazos distintivos, pero no divisible en unidades discretas de rango inferior. Se trata de la distinción discreto/continuo, y el texto, según la perspectiva elegida, podría ser considerado bien como una suma de elementos discretos, bien como unidad continua. También se debería poder considerar como texto a un conjunto de textos homólogos bajo alguna relación.

El mismo mensaje puede presentarse como texto, como parte de un texto o incluso como conjunto de textos. Los textos podrían disponerse de acuerdo a diferentes modos de clasificación: el texto tomado en sí mismo en el cuerpo orgánico propuesto por el autor, el conjunto que se puede crear a posteriori con todos los textos que se pueden agrupar en una categoría (novela,...), hasta

[3] Podría ser criticado de una sobrevaloración de los textos, de los discursos, como si en la palabra se agotase toda la actividad humana.; es decir, de los modelos del mundo hay que pasar al mundo mismo; pero Lotman es tajante ("el mundo no es un texto. No tiene sentido") subrayando que el sentido del mundo es nuestro discurso sobre el mundo, que por ello es competencia del hombre la actividad de dar sentido al mundo. Una actividad semiótica que el individuo puede ejercer tan sólo en conexión con la colectividad, es decir, con la cultura (Segre 1981: 26).

[4] Whorf sugiere que el lenguaje, aunque parte de la cultura, es más importante y poderoso que los otros componentes de la misma. La importante influencia de la cultura sobre el pensamiento, afirma, es abordable a través del estudio del lenguaje, y, aunque éste es una parte de la cultura, tiene un marcado efecto sobre el pensamiento. Whorf duda en afirmar si el lenguaje es una parte de la cultura o, al revés, si la cultura es una parte del lenguaje, y no se decide por cuál de los dos es la fuerza determinante a la que deben ser reducidos los demás fenómenos (Schultz 1990: 15 y 17).

THÉMATA. Revista de Filosofía, No 49 enero-junio (2014) pp.: 185-202 doi: 10.12795/themata.2014.i49.10 
la totalidad de textos de una cultura. Las relaciones entre cultura y texto son muchas y con diversas funciones, pero ¿es posible la cultura sin escritura y, por tanto, sin textos? (Lotman 1993) ¿es posible concluir, por el hecho de que en el espacio eurasiático el desarrollo histórico haya procedido de esta manera, que una civilización no pueda desarrollarse sólo con una cultura oral? La existencia milenaria de culturas en la América preincaica nos proporciona pruebas convincentes de la estabilidad de esa civilización, y las altas expresiones de cultura alcanzadas demuestran claramente sus posibilidades. Para que la escritura se haga indispensable tienen que darse una inestabilidad de las circunstancias históricas, un dinamismo, unas situaciones impredecibles, unas necesidades que en las múltiples traducciones semióticas nacen en presencia de frecuentes y duraderos contactos entre marcos culturales distintos.

El mundo de la cultura oral está lleno de símbolos. La introducción de la escritura posiblemente no enriquezca sino que empobrezca la estructura semiótica de una cultura. Es significativo que el Sócrates platónico asocie la escritura, no con el progreso de la cultura, sino con la pérdida del alto nivel que ésta había alcanzado en la sociedad oral.

Una cultura escrita tiende a ver el mundo creado por Dios o por la naturaleza como un texto y trata de leer la información que éste contiene. Por consiguiente, se busca el significado fundamental en el texto escrito -sacro o profano- y después en el ambiente. Los fenómenos naturales son percibidos como signos memorísticos o predictivos. El hecho de que, en el pacto suscrito con Noé, el Dios de la Biblia dejara como testamento el arco iris, mientras que a Moisés le dejara las tablas de la ley escritas, simboliza claramente el paso de la orientación tipológica hacia otra forma diferente de memoria. La escritura es una forma de memoria. Y es que la conciencia colectiva, que siente la necesidad de fijar algo importante para toda la colectividad, tiene sus mecanismos de memoria colectiva, entre ellos es necesario colocar la escritura.

Una característica de la conciencia "escrita" es la atención a la relación causa-efecto y al resultado de la acción: no se registra en qué momento es oportuno sembrar, sino cómo fue la cosecha en un determinado año; a esta misma conciencia va ligada una acentuada atención a la dimensión temporal y, como resultado de ello, nace el concepto de historia. Podemos decir que la historia es uno de los subproductos de la escritura.

Tanto si nos centramos en el tema de la cultura como en el de la comunicación, la memoria es condición sine qua non. En el primer caso, podemos considerar incluso una identidad entre cultura y memoria. ${ }^{5}$ En el segundo caso, para que sea posible la comunicación sería necesario la existencia de una memoria común, más que hablar de la coincidencia, puesta en común o co-

[5] "Nosotros entendemos la cultura como memoria no hereditaria de la colectividad, expresada en un sistema determinado de prohibiciones y prescripciones" (Lotman 1979: 71).

THÉMATA. Revista de Filosofía, N 49 enero-junio (2014) pp.: 185-202 doi: 10.12795/themata.2014.i49.10 
munidad de códigos. Sperber habla de la necesidad de un saber mutuo: "cada información contextual utilizada para la interpretación del enunciado debe no solamente formar parte del saber del locutor y del destinatario, sino también del saber mutuo" (Lotman 1995: 217); saber mutuo evidentemente relacionado con esa memoria común del emisor y del destinatario de que nos habla Lotman, quien ha sostenido que el receptor no mantiene una relación pasiva con el mensaje/discurso/texto; por el contrario, esta relación tiene la naturaleza de un diálogo donde se puede constatar la presencia en el emisor y el destinatario de una memoria común. Por eso el mensaje/discurso/texto no debe ser evaluado sólo sobre la base de la capacidad de hacerse comprender por un determinado destinatario, sino también según el grado de incomprensión para otros.

La trasmisión de información en el interior de una "estructura sin memoria" garantiza un alto grado de identidad. Si emisor y destinatario estuvieran dotados de códigos iguales y totalmente exentos de memoria, la comprensión entre ellos sería perfecta, pero el valor de la información trasmitida sería mínimo y la misma información rigurosamente limitada. La comunicación normal, y aún más, el normal funcionamiento de la lengua, llevan implícito el supuesto de una identidad de partida entre el hablante y el oyente.

El estructuralismo tradicional, como el formalismo ruso, se basan en considerar el texto como un sistema cerrado, autosuficiente, organizado de manera sincrónica. Su aislamiento era no sólo temporal, sino también espacial, del público y de todo lo que estuviera situado fuera de él. Bajtin plantea su divergencia fundamental y definitiva con el formalismo y sus herederos estructuralistas y postestructuralistas afirmando que todo enunciado posee forzosamente una genealogía, un origen (Game 1999:63).

La fase contemporánea de estos estudios (Lozano 1995), complicó tales principios. El texto es percibido en el tiempo como un momento artificialmente fijado entre el pasado y el futuro. El pasado se deja aprehender en dos manifestaciones: la memoria directa del texto, encarnada en su estructura interna, en su inevitable contradicción, en la lucha inmanente con su sincronismo interno, y externamente, como correlación con la memoria extratextual. "Es como si el espectador" -colocándose con el pensamiento en aquel tiempo presente que es realizado en el texto- "dirigiese su propia mirada al pasado, que se va estrechando como un cono cuya punta se apoya en el tiempo presente." Dirigiéndose a su vez hacia el futuro, el público se hunde en un haz de posibilidades que no han realizado todavía su elección potencial.

La vista retrospectiva permite al historiador analizar el pasado desde dos puntos de vista: encontrándose en el futuro respecto al suceso descrito, ve frente a sí toda la cadena de las acciones realmente realizadas, transformándose en el pasado bajo la observación de la mente; y mirando desde el pasado hacia el futuro conoce ya los resultados del proceso, como si estos resultados todavía no se hubieran alcanzado y fuesen ofrecidos al lector como predicciones. En el curso de este proceso la casualidad desaparece totalmente de la historia. 
La posición del historiador se puede comparar a la de un espectador que asiste a una obra de teatro por segunda vez. Conoce el desenlace de un argumento en el que no hay nada de imprevisible, pero, a la vez, tiene de nuevo el sentimiento de lo ignoto, como si no supiera el final. Estas experiencias se funden en un cierto sentimiento paradójico.

De ese modo, dice, el acontecimiento acaecido se presenta en una interpretación de estructura múltiple: de un lado como la memoria de una explosión apenas vivida; del otro adoptando los rasgos de una inevitable predestinación.

La mirada del historiador es un proceso secundario de transformación retrospectiva. El historiador mira el acontecimiento con una mirada dirigida del presente al pasado. Se reflexiona desde el momento actual. Esta mirada, por su misma naturaleza transforma el objeto de descripción. El cuadro de acontecimientos, caóticos para el simple observador, sale de las normas del historiador ulteriormente organizado. Es propio de este último partir de la inevitabilidad de lo acontecido, pero su actividad creativa se manifiesta en otro lugar: parte de la multiplicidad de los hechos conservados por la memoria, y llega con la máxima fiabilidad al punto conclusivo, cubierto superficialmente por un velo de conjeturas arbitrarias y de vínculos de causa y efecto falsamente convincentes, pero en cuya base existe la causalidad. El retrato de los hechos adquiere bajo la pluma del historiador un carácter casi místico. Estas consideraciones sobre la historia y el historiador salen al paso de ciertas concepciones sobre los estudios semióticos como ahistóricos. En sus inicios algunos sectores de la cultura fueron aislados del espacio histórico que los rodeaba; pero, al plantearse más tarde la relación entre la semiosis y el mundo externo, la semiótica ha entrado necesariamente en el espacio de la historia. Si cierta historiografía se ha ocupado de procesos lentos, de transformaciones imperceptibles, estudios como los que la Escuela de Tartu ha dedicado al arte, "hija de la explosión", han pasado de una preocupación por los procesos graduales en el seno de la lingüística a los denominados procesos explosivos. El estudio de los procesos de larga duración, de extensión plurisecular, y el estudio del resplandor de la explosión, de la brevedad atemporal, son dos aspectos del análisis histórico que no sólo no se excluyen, sino que se interrelacionan. La realidad histórica es siempre más compleja que los modelos de los historiadores, aunque no podría ser comprendida sin la existencia de éstos.

Como la "memoria del género" introducida por Bajtin, el texto restaura el recuerdo y genera nuevos sentidos. Lotman ve en el texto la intersección de los puntos de vista entre el autor y el público. El presente, a su vez, en relación con el futuro, es un estallido de espacio de sentido todavía no desplegado. Contiene en sí todas las posibilidades de desarrollo futuras. La elección de una de ellas no está determinada ni por las leyes ni por la casualidad ni por la probabilidad: en el momento de la explosión estos mecanismos se vuelven inactivos. La elección del futuro se realiza como casualidad. 
El momento de la explosión se coloca en la intersección de pasado y futuro en una dimensión casi atemporal. La idea de intemporalidad no está ligada a la real cronología del proceso que en la realidad puede durar incluso mucho. La caída del imperio romano sería en esta perspectiva un típico proceso explosivo, aunque se haya dilatado algunos siglos.

La cultura como conjunto complejo se halla formada por estratos que se desarrollan a diferente velocidad, de modo que cualquier corte sincrónico muestra la simultánea presencia de varios estados. Las explosiones, en algunos estratos, pueden unirse a un desarrollo gradual en otros. Esto no excluye su interacción. La dinámica de los procesos en la esfera de la lengua y de la política, de la moral y de la moda, demuestran las diferentes velocidades de movimiento de estos procesos. Centrémonos un momento en el caso de la moda y el arte.

\section{Moda y arte}

Un tema recurrente de toda la obra lotmaniana es el de la moda, a la que califica de "caprichosa", "voluble", "extraña" (Lotman 1999: 113), que subraya la ausencia de motivación, la aparente arbitrariedad de un movimiento que se convierte en metrónomo del desarrollo cultural. Permite observar la constante lucha entre la tendencia a la estabilidad, a la inmovilidad y la orientación opuesta hacia la novedad, la extravagancia: todo entra en la representación de la moda, casi la visible encarnación de la novedad inmotivada.

La moda es siempre semiótica (Lotman 2011: 107), transformando lo significante en significativo. El vestido es un texto que se dirige a alguien; por eso es fundamental el punto de vista del observador.

El semiólogo ruso describe la ostentosa simplicidad de Napoleón, quien, sin embargo, prestaba gran atención a los uniformes de sus mariscales y generales, a su teatralidad y espectacularidad. La simplicidad del uniforme de Napoleón, que destacaba frente al manierismo de sus oficiales, subrayaba que, en este caso, era el emperador el observador. La corte y el mundo entero no eran sino un espectáculo montado para él.

Otro ejemplo es la evolución del modo de vestir de Stalin. En los años veinte vestían todos los dirigentes del partido con uniforme de estilo militar. En los años treinta los uniformes de las jerarquías superiores fueron modificados para realzar una mayor solemnidad. Sólo los máximos dirigentes continuaron en una simplicidad espartana, especialmente Stalin que se mantenía como observador. Tras la guerra, cuando mostró en discursos su propia inseguridad frente al pueblo, tuvo en cuenta el punto de vista del observador y adoptó el uniforme de gran mariscal. La ostentosa seguridad de quien observa y controla todo, dio paso a la inseguridad de un hombre preocupado por su propio aspecto. 
Lotman enfatiza la centralidad del arte cuando, sugestivamente, establece una íntima conexión entre arte y proceso histórico, atribuyendo al arte los efectos más importantes y hablando desde la perspectiva epistemológica con la que ha afrontado la historia: la irrupción del arte en el proceso histórico modifica radicalmente su carácter. Si la historia es una ventana que da al pasado, el arte da al futuro, y los cristales de estas ventanas pueden ser espejos. El pasado se percibe como una vía que conduce directamente al presente; y el paso al futuro se configura como una imprevisibilidad.

El arte introduce en la vida aquella libertad que se pierde cuando las ideas se encarnan en la realidad; sea cual sea el momento elegido como objeto de la obra, el presente, el pasado o el futuro, el arte traslada al lector a una esfera de libertad, lo que hace que sea percibido como análogo al futuro.

\section{Texto y códigos de comunicación}

El texto literario construye un modelo del mundo. La semiótica debe realizar la difícil tarea de hallar en un texto determinado lo que representa la realidad, según los estereotipos de una cultura dada, y lo que propone realidades distintas, agazapadas en la nuestra, realizables en el futuro, etc., bajo las semblanzas de prefiguración o deformación, utopía o sátira, esperanza o profanación. El texto artístico está en la cultura, no es la cultura. Lotman insiste en la relación con la realidad. El recorrido sería: realidad-input de textos-cultura-texto artístico-realidad. La insistencia en la realidad como punto de partida y de llegada tiene como razón el defender la función cognitiva y crítica de la literatura y del arte. La superioridad de la obra de arte sobre otras formas de comunicación está en el hecho de que propone un modelo del mundo como si fuera verdadero.

Según Bajtin, "la palabra está preñada de respuesta"; la palabra viva que pertenece al lenguaje hablado está orientada directamente hacia la futura palabra-respuesta: provoca su respuesta, la anticipa y se construye orientada a ella. La palabra viene determinada a su vez por lo que todavía no se ha dicho, pero que viene ya forzado y previsto por la palabra de la respuesta. La palabra nace, así, en el interior del diálogo.

Lotman lo explica: "el texto ha seleccionado al público a su imagen y semejanza". En esta frase se puede encontrar todo un programa en torno a los códigos en la comunicación y una definición de texto que remite etimológicamente al tramado de los hilos de la tela, un mecanismo dinámico capaz de generar nuevas informaciones y que no se mantiene idéntico a lo largo de la transmisión.

Una simple comunicación vista como transmisión de información o como intercambio de mensajes exige, en los esquemas canónicos de la teoría -física o matemática- de la comunicación tal como la concibieron Shanon y 
Weaver o como la formalizó Jacobson, siguiendo a los que él llamaba "ingenieros de la comunicación", un código sustancialmente común entre el emisor y el destinatario. Sin embargo, la coincidencia de códigos (en plural) de emisor y destinatario es posible sólo como suposición teórica y no se cumple jamás completamente. Antes al contrario, el texto de la comunicación se deforma en el proceso de decodificación efectuado por un destinatario que, lejos de caracterizarse por una percepción pasiva, está dotado de competencia comunicativa. Emisor y destinatario no son meros polos, semánticamente neutros, de un continuum de información sino sujetos competentes o meaners (en terminología de Halliday), término que sugiere su capacidad de interactuar y significar. En este sentido convendría concebir la comunicación más como transformación que como simple transferencia o transmisión de información.

Estudios cognitivos que parten de Relevance (1986) de Sperber han querido señalar una supuesta crisis de la disciplina semiótica al considerarla anclada justamente en lo que el autor ha dado en llamar un code model, según el cual no solo los errores de la comunicación (malentendidos, etc.) sino también sus éxitos, se explicaban en función de la existencia o no de códigos comunes, del déficit de códigos y otros muchos factores. Frente a este restringido modelo de código, Sperber, desde un cognitivismo que superaría el supuesto reduccionismo semiótico, propone un inference model en el que los procesos de inferencia son diferentes de los procesos de decodificación. Según sus propias palabras, no se puede hacer abstracción de las diferencias que existen entre la representación semántica de las frases y los pensamientos comunicados por medio de enunciados que no se agotan en la decodificación y exigen reglas de inferencia.

La presencia de dos partenaires de la comunicación parecidos y, al mismo tiempo, diferentes es importantísima, pero no es la única condición, para el surgimiento de un sistema dialógico. El diálogo entraña la reciprocidad y la mutualidad en el intercambio de información. Para eso es necesario que el tiempo de transmisión sea relevado por el tiempo de recepción. Eso supone un carácter discreto: la posibilidad de hacer interrupciones en la transmisión informacional. Esta capacidad de entregar información en porciones es una ley universal de los sistemas dialógicos, desde la secreción de sustancias odoríferas en la orina de los perros hasta el intercambio de textos en la comunicación humana. Se ha de tener en cuenta que el carácter discreto puede surgir en el nivel de la estructura allí donde en la realización material de la misma existe un relevo cíclico de períodos de alta actividad y períodos de máxima disminución de ésta. De hecho, se puede decir que el carácter discreto en los sistemas semióticos surge cuando se describen procesos cíclicos con el lenguaje de una estructura discreta. En la historia de la cultura se pueden distinguir períodos en los que un tipo de arte, al hallarse en un momento de prestigio, trasmite sus textos a otros sistemas semióticos. Pero esos períodos son relevados por otros 
en los que ese arte pasa a la recepción. De hecho, no hay una interrupción, aunque al estudiarlo lo parezca. Unos estilos comienzan su expansión mientras otros parecen interrumpirse. Este mismo fenómeno explica los movimientos culturales como Renacimiento, Barroco, Clasicismo o Romanticismo que, al haber sido generados por factores universales para la cultura dada, deben diagnosticarse sincrónicamente en el dominio de las diversas manifestaciones artísticas e intelectuales. Pero en el tejido real de la cultura, la ley regular es la no-sincronía; mientras el arte transmisor se halla en su apogeo, empieza a manifestar rasgos de espíritu innovador y de dinamismo que le llevará al nuevo estilo. Los destinatarios, por lo general, todavía están viviendo la etapa cultural precedente. Lo mismo ocurre con respecto a los contactos entre áreas culturales diferentes, o al diálogo entre el centro y la periferia de una cultura, o entre los estratos altos y bajos.

El diálogo debe también poseer otra propiedad, el texto trasmitido y la respuesta por él recibida deben formar una unidad, es decir, el texto trasmitido debe, adelantándose a la respuesta, contener elementos de transición a la lengua ajena. De lo contrario el diálogo es imposible. A esto se vincula el hecho de que la literatura del siglo XIX, para ejercer influencia sobre la pintura, debió incluir en su lenguaje elementos pictóricos. En este sentido, se puede decir que el lenguaje precede a la cultura y la genera.

Si el estructuralismo consideraba el texto como piedra angular, como entidad separada, aislada, estable y autónoma, las investigaciones semióticas contemporáneas, aunque lo toman también como punto de partida, han dejado de verlo como objeto estable, para concebirlo como una intersección de los puntos de vista del autor y del público. Lotman ha insistido en ver el acto comunicativo, no como una transmisión pasiva de información, sino como una recodificación, si se quiere utilizar la jerga informacionalista, o más precisamente, una traducción. Desde el mismo informacionalismo ya se había sostenido que el receptor debe reconstruir el mensaje recibido, por lo que la incomprensión, la comprensión incompleta, etc. no son productos laterales del intercambio debidos a ruido -irrupción del desorden, de la entropía, de la desorganización en la esfera de la estructura de la información- en el canal de la comunicación, y, por tanto, algo no inherente a la comunicación sino que, por el contrario, corresponden a su esencia real. Consideraciones estas ilustradas en la obra de Lotman con numerosos ejemplos que sirven de advertencia a la hora de enfrentarse al análisis de los textos. Así, en el marco de la cultura medieval, serán diferentes las normas ideales del comportamiento del caballero y del monje. Su comportamiento parecerá sensato, comprenderemos su "significado", sólo si adoptamos para cada uno de ellos estructuras de códigos particulares -cualquier tentativa de emplear otro código hace aparecer tal comportamiento como "sin sentido", "absurdo" o "ilógico", y no lo descifra. 
En un determinado nivel estos códigos resultarán opuestos entre sí. Mas no se trata de la oposición, dice el semiólogo ruso, de sistemas no-conexionados y, por consiguiente, diferentes, sino de una oposición en el interior del mismo sistema.

Lotman y Uspenski daban también un ejemplo extraído de la obra del cibernético Wiener: para los maniqueos el diablo es un ser malévolo que dirige consciente e incondicionalmente su poder contra el hombre; para san Agustín, en cambio, el diablo es fuerza ciega, entropía dirigida sólo objetivamente contra el hombre a causa de la debilidad e ignorancia de éste.

Otra peculiaridad de los textos (culturales) es su movilidad semántica. El mismo texto puede proporcionar a sus distintos "consumidores" una información diferente. Sirva aquí también este ejemplo; el lector moderno de un texto sagrado del Medievo descifra la semántica reuniendo códigos diferentes de los usados por el creador del texto. Además cambia igualmente el tipo de texto: en el sistema de su creador pertenecía a los textos sagrados, mientras que en el sistema del lector pertenece a los artísticos.

Si el texto "selecciona" el público a su imagen y semejanza, fija unos confines que, trasladados a la cultura, establecen una oposición, que puede considerarse un universal cultural, un "nosotros/ellos" en la que se encuentran correlatos topológicos como "dentro/fuera", "interno/externo", etc. Pensemos, como ejemplo de la oposición "nosotros/ellos", en la que oponía culturalmente los griegos a los bárbaros que vivían "fuera" de la polis. La etimología de bárbaro (gr.: barbaros, lat.: barbarus) viene de bar-bar, balbucear, que, por la onomatopeya, sugiere incomprensión.

Weinrich ha señalado cómo la palabra bar-bar presenta un perfil fonético caracterizado por la unión de la consonante "b" y de la vocal "a" en conjunción con una líquida, en este caso " $r$ ". Existe un contraste máximo entre la clausura de la oclusiva bilabial "b" y la abertura extrema de la vocal "a". En las más diferentes lenguas del mundo se encuentra el mismo contraste para designar "mamá" y "papá" en la primera infancia. Por Jakobson sabemos que el lenguaje infantil se constituye sobre la base de recurrencias fonéticas muy contrastadas. Los grandes contrastes son más fáciles de percibir y de realizar por los niños y, por tal razón, perduran más tiempo en el estado de afasia. Por ello se puede establecer una analogía entre el bárbaro y el niño que balbucea muy rápidamente y de modo incomprensible.

No debe sorprender, pues estamos inmersos en el espacio de la lengua, que esa oposición "nosotros/ellos", "los de dentro contrapuestos a los de fuera", se base en la capacidad de reconocer la propia lengua, una lengua capaz de sorprenderse ante otra que incluso no es reconocida como tal, que carece de gramática y apenas resulta perceptible como un balbuceo o una insuficiente expresión infantil. Los griegos tienen una lengua, los bárbaros, no. 
La adaptación semiótica a las reglas de una civilización externa suele estar ligada a la dicotomía "cultura/barbarie". Los antiguos griegos llamaban bárbaros a los persas y egipcios, que les superaban por la riqueza de su tradición cultural; los romanos consideraban bárbaros a los cartagineses y a los griegos. Los árabes, poco después de haber entrado en el mundo civil, utilizaban la palabra adjami, que tenía el mismo significado que bárbaro, para definir a los persas, herederos de aquella antigua y elevada cultura contra la cual habían luchado, por la influencia sobre el mundo musulmán. En fin, Montaigne nos dice: "Cada cual llama barbarie a lo que no forma parte de su costumbre."

En la realidad, dice Lotman, encontramos siempre la presencia del otro: otro hombre -exterior al sistema y no a él-, otra estructura, otro mundo. La función de este otro es inmensa y consiste justamente en el hecho de colocarse fuera de todas las funciones y de irrumpir perturbadoramente en el mundo habitual. Toda cultura crea su propio sistema de marginales, de desechados, aquellos que no se inscriben en su interior y que una descripción sistemática y rigurosa excluye. La irrupción en el sistema de lo que es extrasistemático constituye una de las fuentes fundamentales de transformación de un modelo estático en uno dinámico.

Las diferencias entre el emisor y el destinatario son de experiencia semiótica y de estructura de código. Una cierta comodidad heurística ha hecho que los estudios de comunicación establecieran compartimentos estancos para describir los distintos elementos -emisor, mensaje y destinatario- del sistema comunicativo, considerando el texto como un anillo pasivo de la transmisión de una información que es la misma a la entrada (emisor) y a la salida (destinatario). De ese modo, la diferencia de información en la entrada y en la salida es posible sólo como consecuencia de las interferencias en el canal y sancionada como una imperfección técnica del sistema. Sin embargo, tal y como estamos viendo, ese texto que se deforma, modifica, transforma, tiene una función: la de producir nuevos significados. Lo que podría ser considerado una imperfección técnica del sistema es, en cambio, en este caso, una norma, y la característica estructural del trabajo del texto que Lotman gusta de llamar "mecanismo pensante" es su heterogeneidad interna. Un mecanismo constituido por un sistema de espacios semióticos heterogéneos en el interior de los cuales circula la información transmitida. En este caso, el texto no es la manifestación de un solo lenguaje. Para producirlo son necesarias al menos dos lenguas; ningún texto de este tipo puede ser descrito adecuadamente desde el punto de vista de un único lenguaje. El texto es concebido como un espacio semiótico en el interior del cual los lenguajes interactúan, se interfieren y se organizan jerárquicamente.

En tanto que ciencia de la comunicación, la semiótica se fue desarrollando sobre unos textos que se repiten y su estructura. La importante investigación lotmaniana -y en general de toda la Escuela de Tartu- sobre los textos artísticos, únicos susceptibles de describir la tensión entre lo que se repite y 
lo irrepetible, han ampliado los confines de la disciplina, al considerar no sólo la transmisión de mensajes ya dados sino también la elaboración de mensajes nuevos. Y si para trasmitir información es suficiente un único canal (una única lengua), para elaborar una información nueva la estructura mínima requerida es de, al menos, dos. De ahí la importancia de los problemas conectados al poliglotismo, a la traducción y a la traducibilidad. ${ }^{6}$

El dialogismo -sistema humano de comunicación verbal- de Bajtin, abordado en los planos interpersonal e interdialógico, en los cuales los individuos y su habla están en un mismo plano, en el que son móviles y no fijos, plantea el mundo como una incesante actividad y la vida como sucesos, cada uno de ellos responsable ante los demás, es decir, comunicados entre sí. El lenguaje como un todo dinámico se presenta como un diálogo entre toda suerte de influencias, de sublenguajes, "heteróglota de la cabeza a los pies", y se caracteriza por "la coexistencia socio-ideológica entre el presente y el pasado, entre diferentes épocas del pasado, entre diferentes grupos socio-ideológicos del presente, entre múltiples tendencias, cada una de las cuales posee una forma y una encarnación particular" (Game 1999: 63). En este juego incesante, las palabras, las frases, el habla, son actos que constituyen en su constante variedad, lo que Bajtin llama una "arquitectura de puntos de vista". Todos estos lenguajes-lengua, que representan otros tantos orígenes sociales, culturales, geográficos, diferentes, se mueven, evolucionan y "juegan" unos con otros en función de las fuerzas que actúan sobre la sociedad.

El problema del texto está ligado de modo orgánico a un aspecto pragmático, al uso que el destinatario hace del enunciado recibido. El elemento externo, sea otro escrito, el lector -que puede verse como otro texto- o el contexto cultural, es necesario para que se cumplan las posibilidades virtuales de generar nuevos sentidos. En la relación pragmática que se establece entre el texto y el destinatario/público la transformación de la consciencia de éste es pues la manifestación del mecanismo del texto en el proceso de su funcionamiento.

\section{Semiosfera}

Se puede suponer, por tanto, que sistemas constituidos por elementos netamente separados uno de otro y funcionalmente unívocos no existen en la realidad en una situación de aislamiento. Ninguno de ellos, tomado por separado, tiene capacidad de trabajar. Sólo funcionan al estar sumergidos en un

[6] Schultz señala que la paradoja de la traductibilidad aparece tan pronto como consideramos la defensa de Whorf del principio de relatividad lingüística en sus estudios de los lenguajes de los nativos americanos como los hopi; si el principio de relatividad lingüística, tal como lo argumenta Whorf, fuese verdad, sería imposible para nadie traspasar las categorías de su propio lenguaje nativo para aprender las categorías de otro lenguaje diferente. Por tanto, concluye Schultz, el principio de relatividad lingüística es falso (Schultz 1990: 27).

THÉMATA. Revista de Filosofía, No 49 enero-junio (2014) pp.: 185-202 doi: 10.12795/themata.2014.i49.10 
continuo semiótico, completamente ocupado por formaciones semióticas de diversos tipos y que se hallan en diversos niveles de organización. Lotman propone integrar los distintos componentes en lo que ha dado en llamar semiosfera, un concepto que ofrece ciertas analogías con el de biosfera, introducido por el biogeoquímico Vladimir Ivanovich Vernadski:

\footnotetext{
“Todas las condensaciones de la vida están ligadas entre sí de la manera más estrecha. Una no puede existir sin la otra. Este vínculo entre las diversas películas y condensaciones vivas, y el carácter invariable de las mismas, son un rasgo inmemorial del mecanismo de la corteza terrestre, que se manifiesta en ella en el curso de todo tiempo geológico". "La biosfera tiene una estructura completamente definida, que determina todo lo que ocurre en ella, sin excepción alguna (...). El hombre, como se observa en la naturaleza, así como todos los organismos vivos, como todo ser vivo, es una función de la biosfera, en un determinado espacio-tiempo de ésta" (Lotman 1995: 3).
}

También en las cuestiones de semiótica es posible un enfoque análogo. Se puede considerar el universo semiótico como un conjunto de distintos textos y de lenguajes cerrados unos con respecto a otros. Entonces todo el edificio tiene el aspecto de estar constituido de distintos ladrillitos. Sin embargo, parece más fructífero el acercamiento contrario: todo el espacio semiótico puede ser considerado como un mecanismo único (o como un organismo). Resulta primordial no uno u otro ladrillito, sino el "gran sistema", denominado semiosfera, el espacio semiótico fuera del cual es imposible la existencia misma de la semiosis.

Así como al pegar distintos filetes no obtenemos un ternero, pero al cortar un ternero sí podemos obtener filetes, al sumar los actos semióticos particulares, no obtenemos tampoco un universo semiótico. Por el contrario, sólo la existencia de tal espacio -de la semiosfera- hace realidad el acto del signo particular.

Una de las nociones fundamentales ligadas a la definición semiótica es la de "confín" (Lozano 1995: 223-224), pero que Desiderio Navarro en su traducción de Acerca de la semiosfera (Lotman 1979: 4) traduce como "frontera". En todo caso, es difícil imaginarlo en un concepto tan abstracto como el de semiosfera. Para Lotman el confín semiótico es la suma de los filtros lingüísticos de traducción.

Pasando a través de dichos filtros, el texto es traducido a otra lengua (o lenguas) que se encuentran fuera de la semiosfera dada. Su clausura se manifiesta por el hecho de que no puede tener relaciones con textos que le son extraños desde un punto de vista semiótico, o con no-textos. Para que un texto adquiera realidad en la semiosfera, es necesario traducirlo a una de las lenguas de su espacio interno, semiotizar los hechos no semióticos. Así visto, el concepto de "confín" se relaciona con el de individualidad semiótica. Por ello, el lingüista de Leningrado describe la semiosfera como "personalidad semiótica". Pero el confín de la personalidad como fenómeno de la semiótica histórico-cultural depende del criterio de codificación. Un ejemplo: en ciertos sistemas la 
mujer, los hijos, los siervos, los vasallos pueden formar parte de la personalidad del cabeza de familia y no tener una individualidad independiente. En otros sistemas pueden ser considerados personalidades distintas. El semiólogo ruso pone el ejemplo siguiente: cuando Iván el terrible castigó, junto al boyardo caído en desgracia, a todos sus siervos, el hecho no fue dictado por el miedo a la venganza, sino por la idea de que jurídicamente los siervos y el jefe de la casa constituían una sola personalidad. Era, por tanto, natural que la punición se extendiera también a aquellos (Lozano 1995: 224).

La semiosfera puede ser explicada de un modo gráfico:

"Imaginemos una sala de museo en la que están expuestos objetos pertenecientes a siglos diversos, inscripciones en lenguas notas e ignotas, instrucciones para descifrarlas, un texto explicativo redactado por los organizadores, los esquemas de itinerarios para la visita de la exposición, las reglas de comportamiento para los visitantes. Si colocamos también a los visitantes con sus mundos semióticos, tendremos algo que recordará el cuadro de la semiosfera" (Lozano 1999: IV).

Lo llamemos o no semiosfera, estamos inmersos en un espacio semiótico del que somos parte inseparable. Separar al hombre del espacio de las lenguas, de los signos, de los símbolos es imposible. La personalidad humana es, al mismo tiempo, isomorfa respecto al universo de la cultura y parte de este universo.

\section{Conclusión}

Lotman tiene una consciencia muy clara del sistema incompleto. Afirma: "No existe cultura dada históricamente donde todos los niveles y subsistemas sean organizados bajo una base estructural rígidamente homogénea y sincronizados en su dinámica histórica". "Numerosos son los ejemplos de pequeños islotes de una organización diferente en el vasto océano de una cultura" (Segre 1984:12). Estas deformidades corresponden, sin duda, a deformaciones de la sociedad correspondiente; ponen de todas formas en peligro la posibilidad de verla como un sistema coherente con desequilibrios tan netos que motivan los cambios eventuales.

El semiólogo ruso está satisfecho de la descripción de cultura, más que como programa, como memoria y de sus lazos con la experiencia histórica. En efecto, para su propia conservación, tiene a la estabilidad como condición de su existencia. Si los cambios intervienen, la situación y el contexto cambian. La cultura los tendría en cuenta necesariamente, pero no se hace responsable de las mutaciones cuyas consecuencias se le escapan.

Debido a que el hombre es incapaz de definir la realidad y de estructurar su mundo exterior e interior haciendo abstracción de la lengua (y de la cultura), estas están conformadas bajo las fuerzas y contrastes que tienen a la realidad en un movimiento continuo. La cultura es capaz de aislar estas fuer- 
zas y contrastes, y de ayudar al hombre a tomar parte activa porque ella los refleja en sí misma, los organiza ideológicamente, hace mitos de la aventura humana. Si se llegara a penetrar en los antagonismos que agitan la cultura, se podría, al mismo tiempo, mejorar la comprensión de su naturaleza y la interpretación de su función. Si es posible en este campo una teoría del cambio, debe desarrollarse en este perímetro especulativo, entre el magma de lo real y nuestro esfuerzo por comprenderlo.

La obra de Lotman, de la que hemos seguido algunas líneas generales aquí, plantea una serie de dudas y preguntas que quedan sin responder y que pueden, por tanto, ser fuente de futuras investigaciones (Segre 1996: 2-3): ¿El núcleo lingüístico colocado en el centro del sistema cultural está necesariamente constituido por una lengua histórica o, más bien, por la facultad del lenguaje? ¿La semiosfera es una entidad única para todo el mundo (como la biosfera), o está provista de fronteras? ¿El modelo del mundo formado por un texto literario está destinado a actuar de forma pragmática liberando sus potencialidades en actos lingüísticos?

$\mathrm{Al}$ ocuparse del confín entre la semiótica y el mundo externo, en esta fase fuera de toda moda, la semiosfera puede ser definida como la ciencia que se ocupa de la teoría y de la historia de la cultura. 


\section{Referencias bibliográficas:}

Bajtin, Mihaíl (1978) "Du discours romanesque", Esthétique et théorie du roman, Paris, Gallimard.

Chelli, Mocef (1980) La parole arabe, Paris, Sindbad.

Derrida, Jacques (1989) Márgenes de la filosofía, Madrid, Cátedra.

Eco, Umberto (1975) La estructura ausente, Barcelona, Lumen.

Game, Jérôme (1999) "Reflejos de un presente perpetuo", Quimera, n ${ }^{\circ}$ 178, marzo.

Lee, Penny (1996) The Whorf theory complex: a critical reconstruction, Philadelphia, John Benjamin Publishing Company.

Lotman, Juri Mijáilovich y Escuela de Tartu (1979), Semiótica de la cultura, Madrid, Cátedra.

(1993) "Consideraciones sobre la tipología de las culturas", Eutopías, $2^{a}$ época, vol. 11.

(1995) Acerca de la semiosfera, Valencia, Episteme.

(2011) "La moda es siempre semiótica", Revista de Occidente n 366.

-Lozano, Jorge (1995) "La semiosfera y la teoría de la cultura", Revista de Occidente $\mathrm{n}^{\circ} 170-171$.

(1999) Prólogo en Juri Mijáilovich Lotman, Cultura y explosión, Barcelona, Gedisa.

(2011) "Fortuny: el pliegue y el laberinto", Revista de Occidente, $\mathrm{n}^{\circ} 366$.

Schultz, Emily A. (1990) "Dialogue at the margins" en Whorf Benjamin Lee (ed.), Bakhtin and linguistic relativity, Wisconsin, The University of Wisconsin Press.

Segre, Cesare (1984) "Culture et texte dans la pensée de Juri M. Lotman", en Morris Halle (ed.), Semiosis, The University of Michigan.

(1981) Semiótica, historia y cultura, Barcelona, Ariel.

(1996) El testamento de Lotman, Valencia, Episteme.

Whorf, Benjamin Lee (1971) Lenguaje, pensamiento y realidad, Barcelona, Barral. 